\title{
Is England closing the international gap in cancer survival?
}

\author{
Sarah Walters ${ }^{\star}, 1$, Sara Benitez-Majano ${ }^{1}$, Patrick Muller ${ }^{1}$, Michel P Coleman ${ }^{1}$, Claudia Allemani ${ }^{1}$, \\ John Butler ${ }^{1,2}$, Mick Peake ${ }^{3}$, Marianne Grønlie Guren ${ }^{4,5}$, Bengt Glimelius ${ }^{6}$, Stefan Bergström \\ Lars Påhlman ${ }^{8}$ and Bernard Rachet ${ }^{1}$ \\ ${ }^{1}$ Cancer Survival Group, London School of Hygiene and Tropical Medicine, Keppel Street, London WC1E 7HT, UK; ${ }^{2}$ Department \\ of Gynaecological Oncology, Royal Marsden Hospital, London SW3 6JJ, UK; ${ }^{3}$ Glenfield Hospital, University Hospitals of Leicester, \\ Groby Road, Leicester LE3 9QP, UK; ${ }^{4}$ Department of Oncology, Oslo University Hospital, Ullevaal, PO Box 4956, Nydalen, NO- \\ 0424 Oslo, Norway; ${ }^{5}$ K. G. Jebsen Colorectal Cancer Research Centre, Oslo University Hospital, PO Box 4953, Nydalen, NO-0424 \\ Oslo, Norway; ${ }^{6}$ Department of Immunology, Genetics and Pathology, Uppsala University, Akademiska sjukhuset, SE-751 85 \\ Uppsala, Sweden; ' Department of Oncology, Gävle Hospital, SE-801 87 Gävle, Sweden and ${ }^{8}$ Department of Surgical Sciences, \\ Uppsala University, Akademiska sjukhuset, SE-751 85 Uppsala, Sweden
}

Background: We provide an up-to-date international comparison of cancer survival, assessing whether England is 'closing the gap' compared with other high-income countries.

Methods: Net survival was estimated using national, population-based, cancer registrations for 1.9 million patients diagnosed with a cancer of the stomach, colon, rectum, lung, breast (women) or ovary in England during 1995-2012. Trends during 1995-2009 were compared with estimates for Australia, Canada, Denmark, Norway and Sweden. Clinicians were interviewed to help interpret trends.

Results: Survival from all cancers remained lower in England than in Australia, Canada, Norway and Sweden by 2005-2009. For some cancers, survival improved more in England than in other countries between 1995-1999 and 2005-2009; for example, 1 -year survival from stomach, rectal, lung, breast and ovarian cancers improved more than in Australia and Canada. There has been acceleration in lung cancer survival improvement in England recently, with average annual improvement in 1-year survival rising to 2\% during 2010-2012. Survival improved more in Denmark than in England for rectal and lung cancers between 19951999 and 2005-2009.

Conclusions: Survival has increased in England since the mid-1990s in the context of strategic reform in cancer control, however, survival remains lower than in comparable developed countries and continued investment is needed to close the international survival gap.

The gap in cancer survival between England and comparable countries has galvanised policymakers and clinicians since EUROCARE first launched its European survival comparisons (Berrino et al, 1995). Evidence that survival is generally lower in England has led to target setting and increased investment, aiming to raise survival in England to the standards achieved elsewhere.

Since the Calman-Hine Report recommended strategic improvements to cancer services in England, there has been a series of policy initiatives to improve survival (Expert Advisory Group on Cancer, 1995). The NHS Cancer Plan for England (Department of Health, 2000) was the second national cancer plan in the world (following Norway's). It emphasised centralisation, specialisation and use of multi-disciplinary teams (MDTs). A further suite of measures to improve prevention, earlier diagnosis and patient management was launched through the Cancer Reform Strategy (Department of Health, 2007) to address

*Correspondence: Dr S Walters; E-mail: sarah.walters@lshtm.ac.uk

Received 18 May 2015; revised 19 June 2015; accepted 24 June 2015; published online 4 August 2015

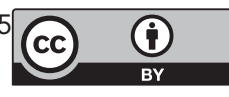


continuing concerns about the survival deficit in comparison to other high-income countries.

In 2009, the Department of Health in England formed the International Cancer Benchmarking Partnership (ICBP), a consortium of epidemiologists, clinicians and policymakers tasked with understanding survival differences between the United Kingdom and five other high-income countries with universal healthcare system coverage: Australia, Canada, Denmark, Norway and Sweden. The ICBP demonstrated steady improvement in survival from colorectal, lung, breast and ovarian cancers in all six countries for patients diagnosed during 1995-2007, but showed that survival in the United Kingdom and Denmark was consistently lower than elsewhere, and there was no evidence of 'catch-up' with the other countries, with the exception of breast cancer (Coleman et al, 2011).

'Closing the gap' therefore remains an on-going focus for UK health policy. At the time of publication of a new national cancer strategy for England, this paper uses the most up-to-date data available to ask whether England is now closing the international gap in cancer survival. Given the influence of the ICBP in defining the recent cancer policy agenda in England, we include the same cancers and countries as that study, with the addition of stomach cancer. We assess progress in a variety of ways, considering both the absolute 'gap' and relative improvement over time.

\section{MATERIALS AND METHODS}

Patients. Individual cancer registrations for 1.9 million adults (aged 15-99 years) diagnosed with a cancer of the stomach, colon, rectum, lung, breast (women) or ovary in England during 19952012, and followed up to 31 December 2013 were obtained from the National Cancer Registry at the Office for National Statistics, linked to the National Health Service Central Register for information on the eventual death of these patients. Cancer registration is a live process, with continual updating of historic registrations, and the current data set was extracted on 22 May 2014.

One- and five-year survival estimates for a further 1.9 million patients diagnosed with one of these six cancers in Australia, Canada, Denmark, Norway or Sweden during 1995-2009, and followed up to 31 December 2009, were extracted from the CONCORD-2 study (Allemani et al, 2015). The CONCORD programme, based at the London School of Hygiene and Tropical Medicine, conducts global surveillance of cancer survival using data from population-based cancer registries. The CONCORD-2 study comprised analysis of individual data for 25.7 million adults (aged 15-99 years) diagnosed with any of ten cancers, and 75000 children diagnosed with childhood acute lymphoblastic leukaemia, from 279 cancer registries in 67 countries.

Whereas the ICBP data were national for Denmark, Norway and the United Kingdom, here the coverage is national for England, Sweden (cf. 43\% coverage in ICBP), Canada (cf. 65\%), Denmark and Norway, and 91\% for Australia (cf. 60\%).

The same inclusion criteria were applied to the National Cancer Registry data for England as to the CONCORD-2 data (Allemani et al, 2015). Patients diagnosed with an invasive, primary, malignant neoplasm of one of the specified sites were eligible for analysis, and they were excluded if their tumour was benign (not malignant) or in situ (malignant but not invasive) or of uncertain behaviour (uncertain whether benign or malignant), or if the organ of origin was unknown. If a patient was diagnosed with two invasive primary tumours at different sites, both tumours were included. If a patient was diagnosed with two primary tumours at the same site, only the first tumour was considered. Patients whose tumour was registered through death certification only were excluded (data quality control statistics by cancer site in Supplementary Webtables 1-6).

The CONCORD-2 topographical definition of tumour sites was applied using the International Classification of Diseases for Oncology (3rd Edition; ICD-O-3). This diverges slightly from the specification used in the production of National Statistics on cancer in England (details available on request; Table 1).

Methods. Methods and tools used in the CONCORD-2 study were applied to the more up-to-date National Cancer Registry data for England in order to compare cancer survival in all six countries for the calendar periods of diagnosis 1995-1999, 2000-2004 and 2005-2009. Survival was also estimated for patients diagnosed during 2010-2012 in England, as well as year-on-year trends for 1995-2012, with follow-up to 2013 (Figure 1).

Cancer patients can die from causes other than their cancer. We estimated net survival, which represents survival in the hypothetical scenario that the cancer in question is the only possible cause of death, factoring out mortality from other causes. This background mortality was estimated using life tables of all-cause mortality rates in the population. We used the same life tables for England as were used in the CONCORD-2 analyses, which were specific to single year of age, calendar year, sex and Government Office Region. To estimate net survival, we used the Stata tool stns (Clerc-Urmès et al, 2014), which implements the Pohar-Perme estimator (Pohar Perme et al, 2012). It takes into account how competing risks of death from other causes increase with age.

One- and five-year net survival were estimated using the traditional cohort method for the periods of diagnosis 1995-1999 and 2000-2004. To estimate 1- and 5-year net survival using a cohort approach, it is necessary to have the potential of 1 or 5 full years of follow-up, respectively, for each patient, which was not the case for patients diagnosed in 2005-2009 in the CONCORD-2 study. A period approach was therefore used for these patients (Brenner and Gefeller, 1996). For comparability, we also used period analysis for the calendar period 2005-2009 in England, even though we did have enough follow-up data to estimate 1-year survival for these patients. For patients diagnosed in England in 2010-2012, we used cohort analysis to estimate 1-year net survival, and a period approach was needed to estimate 5-year net survival (see Supplementary Webfigures 1 and 2 for structure of survival analyses for 1-year and 5-year survival by calendar period).

Year-on-year trends in England for patients diagnosed during 1995-2012, with follow-up to the end of 2013 were estimated using a cohort approach for 1-year net survival. Cohort analysis was also used to estimate 5-year net survival for patients diagnosed up to 2008 , and a hybrid approach was used to predict survival at 5 years in 2013 (Brenner and Rachet, 2004) (see Supplementary Webfigures 3 and 4 for structure of year-on-year analyses of 1year and 5-year survival).

Net survival from cancer varies by age, so apparent differences in overall survival between two cancer patient populations can be driven by underlying differences in the age distributions of those populations. To limit this potential bias, we present agestandardised estimates of net survival, using the same age weights as employed in the CONCORD-2 analyses to enable comparison. These were the International Cancer Survival Standard (ICSS) weights, for which age at diagnosis was categorised into five groups: 15-44 years, 45-54 years, 55-64 years, 65-74 years and 75-99 years (Corazziari et al, 2004).

To assess whether or not England had 'closed the gap' in cancer survival, we interrogated the results in three ways. First, we assessed whether survival for patients diagnosed in 2005-2009 in England equalled or exceeded that in the other countries: where survival was higher in England, or where the 95\% confidence interval for the difference between the two-point estimates included zero, we considered England to have 'caught up' with 
Table 1. Number of patients available for analysis by calendar period of diagnosis, cancer site and country

\begin{tabular}{|c|c|c|c|c|c|c|c|}
\hline & Stomach & Colon $^{a}$ & Rectum $^{b}$ & Lung $^{c}$ & Breast & Ovary $^{d}$ & All cancers \\
\hline $\begin{array}{l}\text { Cancer and ICD-O- } \\
3 \text { topography code }\end{array}$ & $\begin{array}{l}\text { C16.0-C16.6, } \\
\text { C16.8-C16.9 }\end{array}$ & $\begin{array}{l}\text { C18.0-C18.9, } \\
\text { C19.9 }\end{array}$ & $\begin{array}{l}\text { C20, C21.0- } \\
\text { C21.2, C21.8 }\end{array}$ & $\begin{array}{l}\text { C34.0-C34.3, } \\
\text { C34.8-C34.9 }\end{array}$ & $\begin{array}{l}\text { C50.0-C50.6, } \\
\text { C50.8-C50.9 }\end{array}$ & $\begin{array}{c}\text { C48.0-C48.2, C56.9, } \\
\text { C57.0-C57.4, C57.7-C57.9 }\end{array}$ & \\
\hline \multicolumn{8}{|l|}{ Australia } \\
\hline \begin{tabular}{|l}
$1995-1999$ \\
\end{tabular} & 8293 & 37303 & 13695 & 35186 & 47487 & 5485 & 147449 \\
\hline $2000-2004$ & 8643 & 41803 & 16498 & 38751 & 55000 & 6188 & 166883 \\
\hline 2005-2009 & 6885 & 35672 & 13959 & 34088 & 46146 & 5226 & 141976 \\
\hline $1995-2009$ & 23821 & 114778 & 44152 & 108025 & 148633 & 16899 & 456308 \\
\hline \multicolumn{8}{|l|}{ Canada } \\
\hline \begin{tabular}{|l|}
$1995-1999$ \\
\end{tabular} & 14218 & 55969 & 12538 & 92176 & 86819 & 7253 & 268973 \\
\hline $2000-2004$ & 14555 & 65354 & 15421 & 101386 & 95308 & 7717 & 299741 \\
\hline $2005-2009$ & 15223 & 73480 & 21374 & 112161 & 104046 & 10904 & 337188 \\
\hline $1995-2009$ & 43996 & 194803 & 49333 & 305723 & 286173 & 25874 & 905902 \\
\hline \multicolumn{8}{|l|}{ Denmark } \\
\hline 1995-1999 & 2690 & 11195 & 5827 & 16919 & 17202 & 3182 & 57015 \\
\hline $2000-2004$ & 2521 & 11986 & 6407 & 18664 & 19323 & 3104 & 62005 \\
\hline 2005-2009 & 2803 & 13487 & 7535 & 20796 & 22610 & 3042 & 70273 \\
\hline $1995-2009$ & 8014 & 36668 & 19769 & 56379 & 59135 & 9328 & 189293 \\
\hline \multicolumn{8}{|l|}{ England } \\
\hline 1995-1999 & 38477 & 91784 & 41547 & 143113 & 153356 & 24771 & 493048 \\
\hline $2000-2004$ & 34795 & 96411 & 43872 & 144621 & 170152 & 25955 & 515806 \\
\hline 2005-2009 & 30693 & 108276 & 47620 & 155612 & 184247 & 26336 & 552784 \\
\hline $2010-2012$ & 16953 & 70283 & 31063 & 101539 & 116315 & 16194 & 352347 \\
\hline $1995-2012$ & 120918 & 366754 & 164102 & 544885 & 624070 & 93256 & 1913985 \\
\hline \multicolumn{8}{|l|}{ Norway } \\
\hline 1995-1999 & 3324 & 10101 & 5035 & 9466 & 11647 & 2497 & 42070 \\
\hline $2000-2004$ & 2881 & 11268 & 5377 & 10881 & 13339 & 2627 & 46373 \\
\hline 2005-2009 & 2560 & 12440 & 5428 & 12398 & 13665 & 2536 & 49027 \\
\hline $1995-2009$ & 8765 & 33809 & 15840 & 32745 & 38651 & 7660 & 137470 \\
\hline \multicolumn{8}{|l|}{ Sweden } \\
\hline 1995-1999 & 5760 & 15658 & 9209 & 13678 & 27653 & 4486 & 76444 \\
\hline $2000-2004$ & 5097 & 16570 & 9843 & 15491 & 30760 & 4376 & 82137 \\
\hline 2005-2009 & 4463 & 18494 & 10397 & 17575 & 31755 & 4137 & 86821 \\
\hline 1995-2009 & 15320 & 50722 & 29449 & 46744 & 90168 & 12999 & 245402 \\
\hline \multicolumn{8}{|l|}{ Total } \\
\hline 1995-2012 & 220834 & 797534 & 322645 & 1094501 & 1246830 & 166016 & 3848360 \\
\hline \multicolumn{8}{|c|}{$\begin{array}{l}\text { a Includes rectosigmoid junction. } \\
\mathbf{b}_{\text {Includes anus and anal canal. }} \\
c_{\text {Excludes trachea. }} \\
\mathrm{d}_{\text {Includes fallopian tube, uterine ligaments, other and unspecified female organs, peritoneum and retroperitoneum. }} \text { Numbers of patients from other countries are equal to those in the CONCORD-2 study. The number of patients in England differs from the number in England in CONCORD-2 even for } \\
\text { comparable calendar periods because they are from a more up-to-date extract from a live data set. }\end{array}$} \\
\hline
\end{tabular}

Year of diagnosis

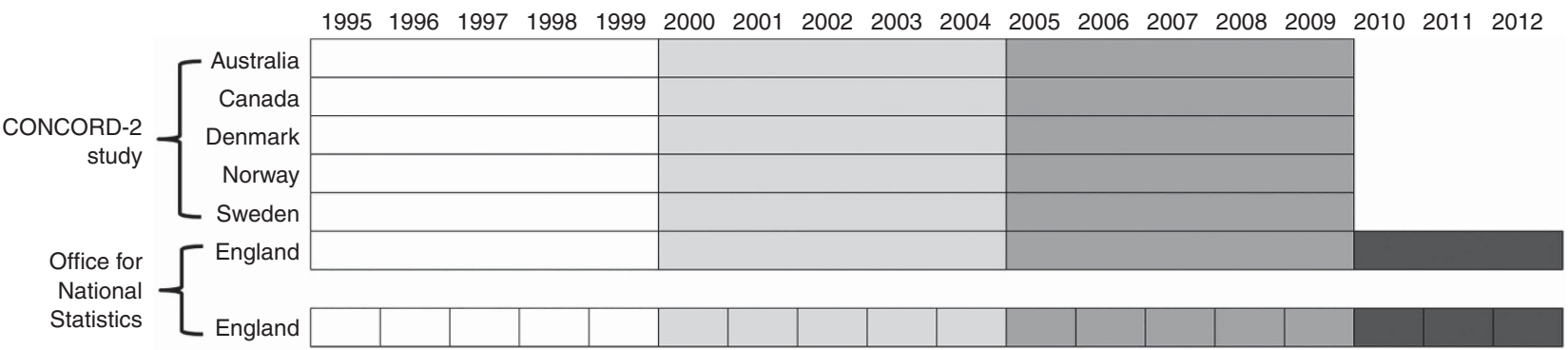

Figure 1. Data sources and periods of diagnosis. The data in our study originated either from the CONCORD-2 study or from the Office for National Statistics. Patients from England were grouped based on their date of diagnosis both by calendar periods of the CONCORD-2 study (for comparability with the other countries) and by year (to allow analysis of yearly changes).

the other country. Second, we asked whether survival in England by 2010-2012 had 'caught up' with the level observed in each other country in 2005-2009. Third, we assessed whether survival in England had improved more than elsewhere during 1995-2009, even if 'catch-up' had not yet been achieved, by considering the confidence intervals for the difference in improvement between England and each other country. To do this, we calculated how much survival had improved in each other country between 19951999 and 2005-2009 and compared this to the amount of improvement in England. We report on these differences with reference to their $95 \%$ confidence intervals; the difference in improvements between England and the other country was considered statistically significant at the $5 \%$ level if the confidence interval for the difference did not include zero. 
Finally, we evaluated the year-on-year trend in England up to 2012, examining whether there had been any acceleration in improvement in survival in more recent years. Using the year-onyear estimates for England for patients diagnosed during 19952012, we calculated the annual change in survival during the periods 1995-1999, 2000-2004, 2005-2009 and 2010-2012. This was the total percentage change in survival (e.g., the arithmetic difference between survival in 1995 and 1999) divided by the number of annual increments (e.g., the period 1995-1999 includes 5 years, but four annual increments).

We identified a panel of 57 clinicians with expertise in one of the six cancers, using purposive sampling of the international clinical networks of senior colleagues in cancer registries and research institutions, ensuring a roughly balanced distribution by country and cancer. We used the Delphi approach to establish consensus of opinion between participants (Dalkey and Helmer, 1963; Hsu and Sandford, 2007). Clinicians were first invited to respond to a semi-structured questionnaire before seeing the results of the survival analyses, to elicit their perceptions of how and why survival at the population level might have changed in their country during 1995-2009. We then distributed the survival analyses and the broad hypotheses arising from the questionnaires, and we conducted in-depth interviews (face to face and by telephone) with individual clinicians. We received responses from 25 clinicians (including 16 questionnaires and 16 interviews), fairly representative of cancers and countries.

\section{RESULTS}

Years of diagnosis 1995-2009. Net survival was highest for patients diagnosed with breast cancer, in the range $94-97 \% 1$ year after diagnosis and $81-86 \%$ at 5 years for those diagnosed in $2005-$ 2009. Survival was lowest from lung cancer, in the range $31-42 \%$ at 1 year and $10-17 \%$ at 5 years in 2005-2009 (Tables 2 and 3).

One- and five-year survival from the gastrointestinal cancers was highest in Australia, and for the gynaecological cancers survival was highest in Australia, Norway and Sweden. Lung

Table 2. Age-standardised 1-year net survival with $95 \%$ confidence intervals for adults (aged $15-99$ years) by calendar period of diagnosis, country and cancer site, and 1995-2009 survival improvement in England minus survival improvement in other countries

\begin{tabular}{|c|c|c|c|c|c|}
\hline & 1995-1999 & 2000-2004 & 2005-2009 & 2010-2012 & $\begin{array}{l}\text { 1995-2009 improvement in } \\
\text { England minus } 1995-2009 \\
\text { improvement in other country }\end{array}$ \\
\hline \multicolumn{6}{|l|}{ Stomach } \\
\hline Australia & $50.4(49.3,51.5)$ & $53.0(52.0,54.1)$ & $55.0(53.8,56.2)$ & \multirow{6}{*}{$47.1(46.3,47.9)$} & $3.5(1.6,5.3)$ \\
\hline Canada & $43.5(42.6,44.3)$ & $45.8(45.0,46.7)$ & $48.0(47.2,48.8)$ & & $3.5(2.1,5.0)$ \\
\hline Denmark & $34.8(32.9,36.7)$ & $36.0(34.0,37.9)$ & $42.5(40.7,44.4)$ & & $0.3(-2.5,3.1)$ \\
\hline England & $35.4(34.9,35.9)$ & $39.8(39.3,40.4)$ & $43.5(42.8,44.1)$ & & \\
\hline Norway & $42.5(40.6,44.4)$ & $46.2(44.2,48.2)$ & $49.3(47.2,51.4)$ & & $1.3(-1.7,4.2)$ \\
\hline Sweden & $42.6(41.2,44.0)$ & $44.6(43.1,46.1)$ & $48.6(47.0,50.2)$ & & $2.1(-0.2,4.3)$ \\
\hline \multicolumn{6}{|l|}{ Colon } \\
\hline Australia & $79.2(78.7,79.6)$ & $81.7(81.3,82.1)$ & $84.3(83.9,84.7)$ & \multirow{6}{*}{$77.2(76.8,77.5)$} & $0.0(-0.8,0.7)$ \\
\hline Canada & $76.4(76.0,76.8)$ & $79.2(78.9,79.6)$ & $81.4(81.1,81.7)$ & & $0.0(-0.6,0.7)$ \\
\hline Denmark & $69.5(68.6,70.4)$ & $71.6(70.7,72.4)$ & $75.2(74.4,76.0)$ & & $-0.7(-2.0,0.6)$ \\
\hline England & $68.7(68.4,69.0)$ & $71.1(70.8,71.4)$ & $73.7(73.5,74.0)$ & & \\
\hline Norway & $76.0(75.1,76.9)$ & $77.0(76.1,77.8)$ & $79.7(78.9,80.4)$ & & $1.4(0.1,2.7)$ \\
\hline Sweden & $77.1(76.3,77.8)$ & $79.3(78.6,80.0)$ & $82.1(81.5,82.8)$ & & $0.0(-1.1,1.0)$ \\
\hline \multicolumn{6}{|l|}{ Rectum } \\
\hline Australia & $83.2(82.5,83.8)$ & $85.6(85.0,86.2)$ & $87.2(86.6,87.8)$ & \multirow{6}{*}{$84.5(84.0,84.9)$} & $2.0(0.9,3.1)$ \\
\hline Canada & $81.4(80.7,82.2)$ & $82.8(82.2,83.5)$ & $84.9(84.4,85.4)$ & & $2.5(1.4,3.6)$ \\
\hline Denmark & $73.9(72.7,75.1)$ & $78.1(77.0,79.1)$ & $81.8(80.9,82.7)$ & & $-1.9(-3.5,-0.3)$ \\
\hline England & $74.3(73.9,74.8)$ & $77.8(77.4,78.3)$ & $80.3(79.9,80.7)$ & & \\
\hline Norway & $81.1(79.9,82.2)$ & $82.2(81.1,83.2)$ & $85.7(84.7,86.6)$ & & $1.4(-0.2,3.0)$ \\
\hline Sweden & $81.9(81.0,82.7)$ & $83.2(82.4,84.0)$ & $84.7(84.0,85.5)$ & & $3.2(1.9,4.4)$ \\
\hline \multicolumn{6}{|l|}{ Lung } \\
\hline Australia & $38.4(37.8,38.9)$ & $40.8(40.3,41.4)$ & $42.3(41.7,42.8)$ & \multirow{6}{*}{$36.7(36.4,37.0)$} & $3.0(2.1,3.8)$ \\
\hline Canada & $36.7(36.3,37.0)$ & $37.8(37.5,38.1)$ & $39.8(39.4,40.1)$ & & $3.8(3.2,4.4)$ \\
\hline Denmark & $25.5(24.8,26.2)$ & $31.5(30.8,32.2)$ & $35.3(34.6,36.1)$ & & $-2.9(-4.0,-1.9)$ \\
\hline England & $24.5(24.2,24.7)$ & $28.3(28.0,28.5)$ & $31.3(31.1,31.6)$ & & \\
\hline Norway & $31.2(30.2,32.1)$ & $32.9(31.9,33.9)$ & $39.4(38.4,40.3)$ & & $-1.4(-2.8,0.1)$ \\
\hline Sweden & $33.9(33.1,34.8)$ & $37.1(36.3,37.9)$ & $40.8(40.0,41.6)$ & & $0.0(-1.2,1.2)$ \\
\hline \multicolumn{6}{|l|}{ Breast } \\
\hline Australia & $95.7(95.5,96.0)$ & $96.4(96.2,96.7)$ & $96.6(96.4,96.9)$ & \multirow{6}{*}{$95.7(95.5,95.9)$} & $3.1(2.6,3.6)$ \\
\hline Canada & $94.9(94.7,95.1)$ & $95.4(95.3,95.6)$ & $95.6(95.4,95.8)$ & & $3.3(2.9,3.7)$ \\
\hline Denmark & $92.4(91.9,92.9)$ & $94.1(93.7,94.6)$ & $95.2(94.8,95.7)$ & & $1.2(0.5,1.9)$ \\
\hline England & $90.2(90.0,90.4)$ & $92.6(92.4,92.8)$ & $94.2(94.1,94.4)$ & & \\
\hline Norway & $95.0(94.5,95.6)$ & $95.7(95.2,96.2)$ & $96.4(95.9,96.9)$ & & $2.6(1.9,3.4)$ \\
\hline Sweden & $96.0(95.7,96.3)$ & $96.7(96.4,97.0)$ & $97.1(96.8,97.4)$ & & $2.9(2.4,3.4)$ \\
\hline \multicolumn{6}{|l|}{ Ovary } \\
\hline Australia & $70.9(69.7,72.1)$ & $73.6(72.4,74.7)$ & $74.8(73.6,75.9)$ & \multirow{6}{*}{$68.1(67.2,68.9)$} & $2.9(1.0,4.9)$ \\
\hline Canada & $68.2(67.1,69.3)$ & $69.3(68.3,70.3)$ & $71.6(70.7,72.5)$ & & $3.5(1.7,5.2)$ \\
\hline Denmark & $61.7(60.0,63.3)$ & $66.2(64.5,67.8)$ & $70.7(69.1,72.3)$ & & $-2.2(-4.7,0.4)$ \\
\hline England & $57.3(56.5,58.0)$ & $60.7(60.0,61.4)$ & $64.1(63.5,64.8)$ & & \\
\hline Norway & $69.1(67.3,70.8)$ & $74.1(72.4,75.7)$ & $74.7(73.1,76.4)$ & & $1.2(-1.4,3.8)$ \\
\hline Sweden & $75.6(74.3,76.8)$ & $77.2(76.0,78.5)$ & $79.5(78.3,80.8)$ & & $2.9(0.8,4.9)$ \\
\hline
\end{tabular}


Table 3. Age-standardised 5-year net survival with $95 \%$ confidence intervals for adults (aged 15-99 years) by calendar period of diagnosis, country and cancer site, and 1995-2009 survival improvement in England minus survival improvement in other countries

\begin{tabular}{|c|c|c|c|c|c|}
\hline & 1995-1999 & 2000-2004 & 2005-2009 & 2010-2012 & $\begin{array}{l}\text { 1995-2009 improvement in } \\
\text { England minus 1995-2009 } \\
\text { improvement in other country }\end{array}$ \\
\hline \multicolumn{6}{|l|}{ Stomach } \\
\hline Australia & $25.9(24.8,27.0)$ & $27.8(26.8,28.9)$ & $27.9(26.7,29.0)$ & \multirow{6}{*}{$20.7(19.9,21.4)$} & $1.9(0.1,3.6)$ \\
\hline Canada & $21.1(20.4,21.9)$ & $23.1(22.3,23.9)$ & $24.8(24.0,25.6)$ & & $0.2(-1.1,1.5)$ \\
\hline Denmark & $13.8(12.3,15.3)$ & $15.3(13.7,16.9)$ & $17.9(16.2,19.5)$ & & $-0.2(-2.6,2.1)$ \\
\hline England & $14.3(13.9,14.7)$ & $16.3(15.9,16.8)$ & $18.2(17.6,18.7)$ & & \\
\hline Norway & $21.1(19.4,22.9)$ & $22.0(20.2,23.9)$ & $24.1(22.1,26.1)$ & & $0.9(-1.9,3.6)$ \\
\hline Sweden & $21.2(19.9,22.5)$ & $21.0(19.6,22.3)$ & $23.2(21.7,24.6)$ & & $1.9(-0.2,3.9)$ \\
\hline \multicolumn{6}{|l|}{ Colon } \\
\hline Australia & $60.3(59.7,61.0)$ & $63.1(62.5,63.7)$ & $64.2(63.6,64.8)$ & \multirow{6}{*}{$58.7(58.3,59.2)$} & $2.3(1.2,3.3)$ \\
\hline Canada & $56.8(56.3,57.3)$ & $60.1(59.6,60.6)$ & $62.8(62.4,63.3)$ & & $0.2(-0.7,1.1)$ \\
\hline Denmark & $48.2(47.1,49.4)$ & $52.1(50.9,53.2)$ & $55.9(54.8,57.0)$ & & $-1.5(-3.2,0.2)$ \\
\hline England & $47.5(47.1,48.0)$ & $50.9(50.5,51.3)$ & $53.7(53.3,54.1)$ & & \\
\hline Norway & $55.9(54.6,57.2)$ & $58.4(57.2,59.6)$ & $61.8(60.6,62.9)$ & & $0.3(-1.5,2.1)$ \\
\hline Sweden & $55.4(54.4,56.5)$ & $59.4(58.5,60.4)$ & $62.5(61.6,63.5)$ & & $-0.9(-2.4,0.6)$ \\
\hline \multicolumn{6}{|l|}{ Rectum } \\
\hline Australia & $59.9(58.9,61.0)$ & $63.8(62.9,64.7)$ & $64.2(63.3,65.1)$ & \multirow{6}{*}{$61.0(60.3,61.8)$} & $3.2(1.6,4.8)$ \\
\hline Canada & $56.5(55.4,57.5)$ & $60.5(59.6,61.5)$ & $62.8(61.9,63.7)$ & & $1.2(-0.4,2.8)$ \\
\hline Denmark & $47.6(46.0,49.2)$ & $53.8(52.2,55.3)$ & $58.4(56.9,59.8)$ & & $-3.3(-5.6,-1.0)$ \\
\hline England & $48.8(48.1,49.4)$ & $53.8(53.3,54.4)$ & $56.3(55.7,56.8)$ & & \\
\hline Norway & $57.8(56.1,59.5)$ & $61.7(60.1,63.3)$ & $64.6(63.0,66.2)$ & & $0.7(-1.8,3.2)$ \\
\hline Sweden & $57.9(56.6,59.2)$ & $59.6(58.4,60.8)$ & $62.0(60.9,63.2)$ & & $3.4(1.5,5.3)$ \\
\hline \multicolumn{6}{|l|}{ Lung } \\
\hline Australia & $13.7(13.3,14.2)$ & $14.8(14.4,15.2)$ & $15.0(14.6,15.5)$ & \multirow{6}{*}{$12.7(12.4,13.0)$} & $1.1(0.4,1.8)$ \\
\hline Canada & $15.1(14.8,15.3)$ & $15.6(15.4,15.9)$ & $17.3(17.1,17.6)$ & & $0.2(-0.2,0.7)$ \\
\hline Denmark & $8.0(7.5,8.5)$ & $9.6(9.1,10.1)$ & $11.3(10.7,11.9)$ & & $-0.9(-1.7,0.0)$ \\
\hline England & $7.0(6.9,7.2)$ & $8.4(8.2,8.6)$ & $9.5(9.3,9.7)$ & & \\
\hline Norway & $10.7(10.0,11.5)$ & $11.7(10.9,12.4)$ & $15.0(14.1,15.8)$ & & $-1.9(-3.0,-0.7)$ \\
\hline Sweden & $12.2(11.6,12.9)$ & $13.3(12.7,14.0)$ & $15.6(14.9,16.4)$ & & $-1.0(-2.0,0.1)$ \\
\hline \multicolumn{6}{|l|}{ Breast } \\
\hline Australia & $84.6(84.0,85.2)$ & $86.4(85.9,86.9)$ & $86.2(85.6,86.8)$ & \multirow{6}{*}{$84.0(83.6,84.4)$} & $5.5(4.6,6.5)$ \\
\hline Canada & $83.7(83.3,84.1)$ & $85.3(84.9,85.7)$ & $85.8(85.5,86.2)$ & & $5.0(4.3,5.8)$ \\
\hline Denmark & $75.8(74.8,76.8)$ & $80.7(79.8,81.6)$ & $82.0(81.1,82.9)$ & & $0.9(-0.5,2.4)$ \\
\hline England & $73.9(73.6,74.3)$ & $78.6(78.3,79.0)$ & $81.1(80.7,81.4)$ & & \\
\hline Norway & $81.5(80.3,82.6)$ & $84.1(83.0,85.1)$ & $85.9(84.9,87.0)$ & & $2.7(1.1,4.4)$ \\
\hline Sweden & $83.8(83.1,84.5)$ & $85.6(84.9,86.3)$ & $86.2(85.5,86.9)$ & & $4.7(3.6,5.8)$ \\
\hline \multicolumn{6}{|l|}{ Ovary } \\
\hline Australia & $36.1(34.8,37.4)$ & $37.0(35.7,38.3)$ & $37.5(36.2,38.8)$ & \multirow{6}{*}{$35.2(34.2,36.2)$} & $1.9(-0.2,4.1)$ \\
\hline Canada & $36.5(35.3,37.7)$ & $35.5(34.4,36.6)$ & $37.5(36.3,38.6)$ & & $2.3(0.4,4.3)$ \\
\hline Denmark & $31.2(29.5,33.0)$ & $33.2(31.5,34.9)$ & $37.3(35.4,39.2)$ & & $-2.8(-5.6,0.1)$ \\
\hline England & $28.2(27.4,29.0)$ & $29.6(28.9,30.4)$ & $31.5(30.8,32.3)$ & & \\
\hline Norway & $36.7(34.7,38.8)$ & $40.2(38.2,42.3)$ & $40.3(38.3,42.4)$ & & $-0.3(-3.4,2.9)$ \\
\hline Sweden & $40.8(39.2,42.4)$ & $42.8(41.2,44.4)$ & $43.5(41.9,45.1)$ & & $0.6(-1.9,3.2)$ \\
\hline
\end{tabular}

cancer survival was highest in Australia, Canada and Sweden. Survival point estimates were slightly lower in England than in Denmark for all cancer sites at 1 and 5 years after diagnosis, with the exceptions of stomach cancer (whole study period) and rectal cancer (in 1995-1999).

There was improvement in 1- and 5-year survival over time for all cancers and in all countries. The mean improvement in 1-year survival among the six participating countries between 1995-1999 and 2005-2009 was 2\% for breast cancer, and 5-7\% for the other five cancers. For 5-year survival, the mean improvement was $6-7 \%$ for colon and rectal cancers, and 3-4\% for the other four cancers.

One- and five-year survival were lowest in England and Denmark for all cancers, and, with few exceptions, remained so throughout 1995-2009 (Figure 2). The exceptions were that by 2005-2009 there was no evidence of difference between Denmark and Canada in 1-year survival from breast and ovarian cancers, and by that time, there was also no evidence of difference in 5-year survival from ovarian cancer between Denmark and either Australia or Canada. By contrast, there is evidence that survival in England during 2005-2009 remained lower than in Australia, Canada, Norway and Sweden for all six cancers.

Calendar period of diagnosis 2010-2012 in England vs 20052009 in other countries. Survival for patients diagnosed with one of these six cancers in England in 2010-2012 generally remained lower than for the equivalent patients diagnosed in 2005-2009 in Australia, Canada, Norway and Sweden (Tables 2 and 3). The exceptions were that there was no evidence of difference in 1-year survival for patients diagnosed with a cancer of the stomach, rectum or breast in 2010-2012 in England compared with patients diagnosed with one of those cancers in 2005-2009 in Canada. Similarly, there was no evidence of difference in 1-year survival for patients diagnosed with stomach cancer in 2010-2012 in England compared with patients diagnosed in 2005-2009 in Norway or Sweden, or for rectal cancer patients in England compared with Sweden at 1 or 5 years after diagnosis.

Trends in cancer survival in England compared with Australia, Canada, Norway and Sweden, 1995-2009. For patients 

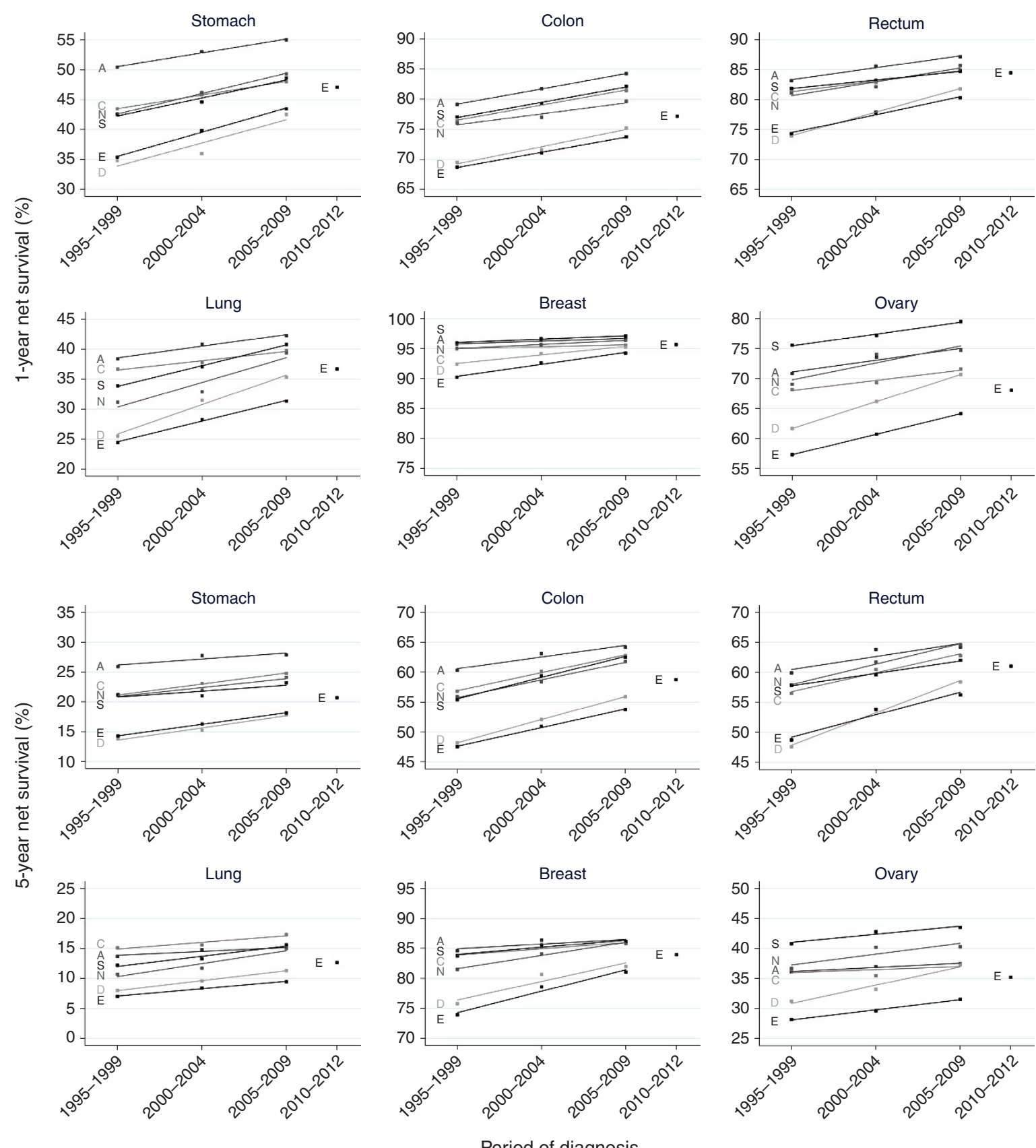

Period of diagnosis

Figure 2. Trends in 1- and 5-year net survival in Australia (A), Canada (C), Denmark (D), England (E), Norway (N) and Sweden (S) by period of diagnosis. Estimates of net survival are presented for the calendar periods of diagnosis 1995-1999, 2000-2004 and 2005-2009. Simple linear regression lines are presented for each combination of country and cancer using data from these three periods, to indicate the average change in survival. An estimate of net survival for England only is also presented for the calendar period of diagnosis 2010-2012.

diagnosed in 1995-1999, the average gap in 1-year survival between England and the four leading countries was $5-14 \%$; by $2005-2009$ it was $2-11 \%$. Equivalent figures for 5-year survival were $6-10 \%$ and 5-9\%, respectively. Although England had not closed the gap in survival with Australia, Canada, Norway or Sweden by 2005-2009, the difference between the improvement in England and the improvement in each other country (improvement in England minus other country improvement) was generally positive (Tables 2 and 3 ). There was evidence at the $5 \%$ level of statistical significance that the improvement in 1-year survival between 1995-1999 and 2005-2009 in England was greater than in Australia and Canada for patients diagnosed with any of these cancers except for cancer of the colon. In addition, there was evidence that the improvement was greater for 1-year survival compared with Norway for colon and breast cancers, and compared with Sweden for rectal, breast and ovarian cancers.

There was also evidence that the improvement in 5-year survival between 1995-1999 and 2005-2009 was greater in England than in Australia for all but ovarian cancer. In addition, the improvement in 5-year survival from rectal cancer was greater than in Sweden, and for ovarian cancer compared with Canada. The improvement in 1- and 5-year survival from breast cancer was greater than in all four leading countries.

Trends in cancer survival in England compared with Denmark, 1995-2009. Survival in Denmark was generally as low as in 

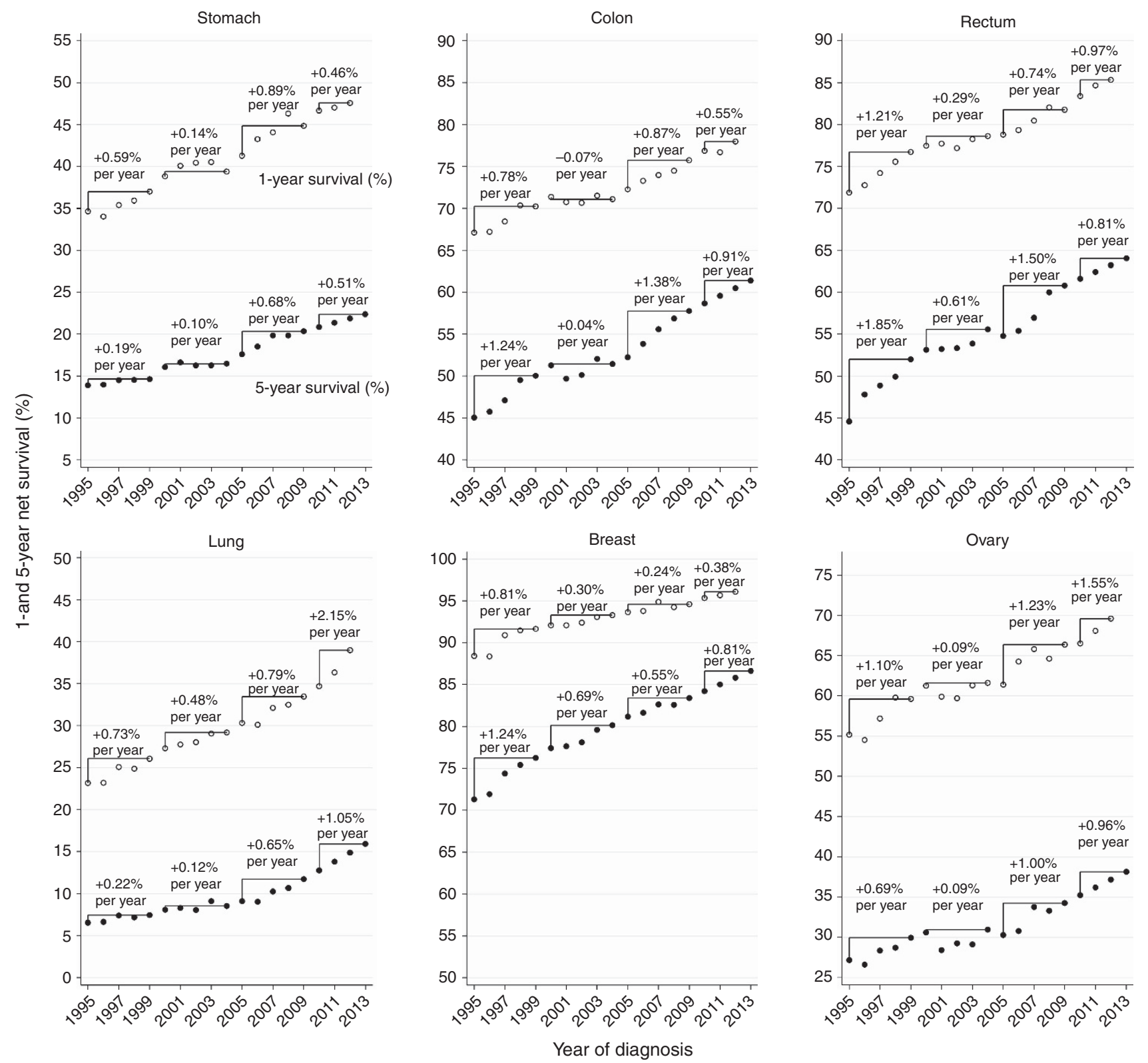

Figure 3. Trends in 1- and 5-year net survival in England by year of diagnosis. Unfilled and filled markers represent estimates of 1-and 5-year net survival, respectively. The average arithmetic improvement in survival between years is shown for the calendar periods 1995-1999, 2000-2004, 2005-2009 and 2010-2013 above the trends.

England in 1995-1999, though significantly slightly higher for lung, breast and ovarian cancer at 1 and 5 years (Tables 2 and 3, Figure 2). The difference in the improvement in England compared with the improvement in Denmark between 1995-1999 and 20052009 was however generally negative, that is, survival improved more in Denmark than in England for these cancers, except for breast cancer at 1 and 5 years, and stomach cancer at 1 year. There is evidence at the $5 \%$ level of statistical significance that survival improved more in Denmark than in England at 1 and 5 years for rectal cancer, and at 1 year for lung cancer. For patients diagnosed in 2005-2009, survival was lower in England than in Denmark for colon and rectal cancers at 1 and 5 years, as well as remaining lower for lung, breast (1-year survival only) and ovarian cancers. One-year survival from lung cancer in Denmark was 1.1\% (0.3$1.8 \%$ ) higher than in England in 1995-1999, but by 2005-2009, survival was $4.0 \%(3.2-4.8 \%)$ higher in Denmark (arithmetic gap in 1- and 5-year survival: Supplementary Webtables 7 and 8).
Survival trends in England during 1995-2012. The year-on-year trends in survival in England during 1995-2012 show a period of relative improvement in net survival in the late 1990s, followed by some years of stability in the early 2000s (Figure 3). During 20052009 , survival again improved more quickly particularly for 1 - and 5 -year survival from colon, rectal and ovarian cancers. For stomach and lung cancers, that pattern can be seen for 1-year survival but less so for 5-year survival, which showed rather little annual improvement before 2005, followed by steady improvement, especially for lung cancer. Breast cancer is the exception: the biggest annual improvements in 1- and 5-year survival occurred in the late 1990s, with smaller but steady improvements since then, particularly for 5-year survival. For lung cancer, 1-year survival has improved more rapidly since 2007/2008, with the annual improvement peaking at $2.2 \%$ per annum for patients diagnosed in 2010-2012. Five-year lung cancer survival also improved, but more slowly, at $1.1 \%$ per annum from 2010. 


\section{DISCUSSION}

Despite steady improvement in survival from stomach, colon, rectal, lung, breast and ovarian cancers in England over the past two decades, survival remained lower than in Australia, Canada, Norway and Sweden for patients diagnosed in 2005-2009, and typically also for patients diagnosed in 2010-2012 in England compared with those diagnosed in 2005-2009 elsewhere. The improvement in survival between 1995-1999 and 2005-2009 was sometimes larger than in the leading countries, particularly in comparison with Australia, Canada and Sweden, leading to some narrowing of the international cancer survival gap. As in England, Denmark also had relatively low survival in comparison to the other four countries in 1995-1999, and cancer control has similarly engendered considerable public debate in that country. Survival generally improved more in Denmark than in England between 1995-1999 and 2005-2009, particularly for lung and rectal cancers. Since 2009, improvement in survival from lung cancer has accelerated in England, and there has also been slight acceleration for ovarian, breast and rectal cancers.

Explaining trends in England. In England, survival generally rose in the late 1990s, followed by a relatively stable period in the early 2000s, after which it improved more quickly, apart from for breast cancer where the greatest gains were seen in the 1990s followed by continued but smaller annual increments throughout the 2000s. Relative stability in survival in the early 2000s was previously identified in an evaluation of the impact of the NHS Cancer Plan for England (Rachet et al, 2009). That strategy, launched in September 2000, proposed to inject an additional $£ 570$ million into cancer services by 2003-2004 to improve prevention, screening, diagnosis and treatment; it established Cancer Networks to oversee specialisation and centralisation of cancer care, following the earlier recommendations of Calman and Hine (Department of Health, 2000). Rachet et al (2009) found that despite the increased investment in services, survival in England did not increase during 2001-2003 as much as in Wales, which had not yet implemented a national cancer plan. These trends were reversed during 20042006, once the new structures and relationships in England were properly established (House of Commons Committee of Public Accounts, 2006).

In order to fully evaluate the impact of the NHS Cancer Plan on survival, the need for data up to the end of 2009 was noted (Rachet et al, 2009). We present those data here, showing that accelerating improvement in survival in England did arise in the mid-2000s. There is consensus among clinicians and auditors that this improvement can be attributed to the national reforms launched during 1995-2000 and their continuing momentum throughout the 2000s, manifest in two revisions to the national strategy and growing emphasis on outcomes monitoring (Department of Health, 2007, 2011). Increased investment, specialisation and centralisation, greater use of MDTs, target-monitoring and performance review are described as key drivers of change in clinical culture and practice, and as the main reasons for improved cancer patient outcomes in England in the 2000s (House of Commons Committee of Public Accounts, 2011).

Treatment in high-volume, specialised centres by sub-specialists with high caseloads is associated with provision of more appropriate treatment and better patient outcomes (Birkmeyer et al, 2003; Hannan et al, 2002; Meyer, 2005), and the drive to increase such centralisation had an impact in England. For example, during 2000-2009, the percentage of women with ovarian cancer receiving surgery who were treated in a specialist trust rose from 43 to $76 \%$, and the number treated by a specialist surgeon (caseload of $>18$ patients per year) rose from 20 to $55 \%$ (Butler et al, 2015). For lung cancer, the number of specialist thoracic surgeons doubled from 44 in 2006 to 84 whole-time equivalent (WTE) in 2014 (personal communication: Sridhar Rathinam, Workforce Lead for the Society of Cardiothoracic Surgeons, 28 April 2015), meaning that more resections were performed by lung specialists, rather than cardiothoracic generalists as in the past (Page et al, 2011). The total number of resections for lung cancer carried out in the United Kingdom and Ireland each year has risen from $c .3000$ in 2001-2002 to $c .5000$ by 2009-2010 (Page et al, 2011), and to over 6000 by 2011-2012 (Society for Cardiothoracic Surgery in Great Britain and Ireland, undated), and the overall percentage of patients resected in England and Wales rose from 9 to $15 \%$ during 2005-2013 (Health and Social Care Information Centre, 2014; The NHS Information Centre, 2006). At the same time, increased specialisation has meant that surgeons are more willing to operate on patients with higher risks of poor outcomes, such as those with co-morbidities or older patients, so, for example, there has been a particularly large increase in the resection of lung cancer patients older than 65 years (Riaz et al, 2012).

Specialisation and improved diagnostic investigations have led to better targeting of treatment and lower postoperative mortality. For example, 30-day mortality following gastrectomy was $4.5 \%$ in 2007-2009 in England (Cromwell et al, 2010), compared with $12.0 \%$ in 24 hospitals in England and Wales in 1999-2002 (McCulloch et al, 2003). It is likely this is partly due to the increase in the percentage of specialist centres that have three or more specialist surgeons (as per the guidelines) from 53\% in 2007 to $95 \%$ in 2012 , and partly because by 2012 nearly all stomach cancer patients eligible for curative treatment were seen by a specialist MDT (Groene et al, 2014). Thirty-day postoperative mortality from colorectal cancer also declined from $6.8 \%$ in 1998 to $5.8 \%$ in 2006, with the biggest decline occurring in 2005-2006 (Morris et al, 2011).

Reforms in cancer services in England have contributed to improved survival over the past two decades for these six cancers, but these changes did not necessarily lead to a closed gap in survival between England and other countries, because despite relative improvement over time, there may remain comparative shortfalls in provision, partly due to the implementation of parallel reforms elsewhere.

Comparison of cancer control reforms. Both Norway and Denmark had launched national cancer plans by 2000, which similarly emphasised centralisation, specialisation and improved patient pathways (Danish National Board of Health, 2000; Norwegian Official Reports, 1997). The early EUROCARE studies had a similar effect in Denmark as they did in England, showing lower survival than in comparable European nations, and prompting public and parliamentary scrutiny of Danish cancer control (Olesen et al, 2009). The Danish cancer plans that were published throughout the 2000s had strong political support and a wide mandate, leading to rapid implementation. Since 2001, surgery for lung cancer has been concentrated from seven departments to four (Starr et al, 2013), ovarian cancer surgery was reduced from 47 departments to 8 during 2004-2007 (Ottesen et al, 2009) and gastric cancer surgery was restricted from 37 departments to 4 university departments during 1999-2007 (Jensen et al, 2007; Jensen et al, 2010). There has also been emphasis on centralisation for colorectal cancer surgery to a greater degree than in England, although this could be because hospitals in England generally treat a larger volume of patients than in Denmark. While in England most hospital trusts conduct surgery for colorectal cancer, in Denmark the number of departments performing surgery for colon and rectal cancers reduced from 38 to 15 during 2003-2012 (Lykke et al, 2013).

One- and five-year survival improved more in Denmark than in England during 1995-1999 to 2005-2009 for all but stomach (1-year) and breast cancer (1- and 5-year), with statistical evidence 
that improvement was greater in Denmark for rectal (1- and 5-year survival) and lung cancer (1-year). This could be because of more comprehensive reform in Denmark or because strategies were better targeted. For example, both England and Denmark identified improving early diagnosis as a priority (Olesen et al, 2009; Richards, 2009), and this may have had more impact in Denmark, where the stage distribution was initially more adverse than in England for some cancers (Maringe et al, 2012; Maringe et al, 2013). Acknowledging the positive impact of these reforms, health policymakers and clinicians in Norway and Sweden are increasingly influenced by Denmark in designing their own cancer strategies, as shown by recent policy in both of those countries to emulate the Danish model of standardised patient pathways (Probst et al, 2012).

Evidence that survival in England improved faster than in other countries during 1995-2009 was strongest in relation to Australia, Canada and Sweden. This could be explained by a partial 'ceiling effect' in those countries, given that they generally had the highest survival at the beginning of the study period. Alternatively, more regionalised health systems in those three countries might have limited the efficacy of national cancer control strategy and the power of national guidelines. While Denmark, England and Norway all introduced national cancer plans by 2000, in the federal countries of Australia and Canada the first provincial cancer plans were launched in the mid-2000s (Cancer Care Ontario, 2004; Cancer Institute New South Wales, 2004), and it was not until 2006-2007 that national oversight bodies were founded to coordinate cancer policy in the various regions. The Canadian Strategy for Cancer Control was published in 2006, leading to the founding of the Canadian Partnership Against Cancer in 2007 (Canadian Strategy for Cancer Control Governing Council, 2006). Cancer Australia was founded in 2006 and has issued a national cancer strategy for 2014-2019. Federalism as well as the remoteness of some rural communities in these countries may pose a larger challenge to the implementation of national standards than in the geographically smaller European countries, possibly explaining the slightly flatter trends in survival for some cancers, such as ovarian (5-year) and lung, despite overall higher survival (Hegney et al, 2005; Tracey et al, 2014). The first Swedish National Cancer Strategy was launched in 2009, and it is as yet unclear how successful it has been in influencing coordinated policy between the Regional Health Boards.

Colorectal oncologists in Sweden and Norway, and lung cancer specialists in England, identified the creation of national quality registries as having been instrumental in the drive towards better care and in improved outcomes in those countries. Populationbased quality registries for rectal cancer were established in Norway and Sweden in 1993 and 1995, respectively, to monitor the rollout of novel surgical techniques and the impact on recurrence and survival (Påhlman et al, 2007; Wibe et al, 2002). The registries were expanded to include colon cancer in 2007 (Guren et al, 2015; Kodeda et al, 2013). Similarly, in England, the national lung cancer audit was initiated in 2004 and now includes all lung cancer patients referred to an MDT in England (Khakwani et al, 2013a; Rich et al, 2011c). Information from these quality registries is regularly fed back to cancer centres and hospital trusts, through public reports, oral presentations and meetings.

Studies have shown that the availability of these data has improved standards, persuading smaller centres to stop operating or to recruit specialist colorectal surgeons in Sweden and Norway, and leading to an increase in histological confirmation for lung cancer in England (Beckett et al, 2012; Påhlman et al, 2007). The data sets have spawned a wealth of research that should lead to better-targeted cancer-control policies (Dahlberg et al, 1998; Guren et al, 2015; Hansen et al, 2007; Rich et al, 2011a, b), and they have been acknowledged as setting the standard for quality registration in Europe (Blum et al, 2014). Other national audits are increasingly available in England, and if these data streams continue to be accessible for research and local-level benchmarking, the prospects for continued harmonisation towards best practice are strong.

Innovations in diagnosis and treatment. In addition to structural reforms, investment and monitoring of outcomes, improvements in survival have also been driven by innovations in diagnostics and treatment over the past two decades. Broadly speaking, innovations have been universally implemented in all six countries, but there are important differences in the timing and degree of provision, which could have contributed to differential survival in the 2000s.

In the case of colorectal cancer, major innovations that could have influenced population-based survival during 19952009 include improvements in preoperative staging through advances in high-resolution radiology, the uptake of total mesorectal excision (TME) surgery, the increased use of preoperative (chemo)radiotherapy and the treatment of metastatic disease. There is evidence that implementation of some of these innovations was slower in England than elsewhere. The use of advanced imaging tools for rectal cancer staging (MRI or, in Australia, positron emission tomography (PET) combined with computed tomography (CT)) has increased in most of these countries since the late 1990s. By 2011-2012, 86\% of rectal cancer patients in England had an MRI before treatment (Scott et al, 2013: p. 69), compared with $97 \%$ of patients in Sweden receiving MRI plus investigation for metastases in the liver and lungs in 2013 (Regionalt Cancercentrum Norr, 2014). TME was pioneered in England in the early 1980s, and shown to reduce locoregional recurrence for rectal cancer. However, TME only became common practice in England much later than in the Nordic countries, where more effective efforts were made to ensure and monitor implementation (e.g., through the Norwegian Rectal Cancer Project and its equivalent in Sweden from 1993/1994) (Guren et al, 2015; Martling et al, 2005; Richards, 2009; Wibe et al, 2002). Although surgery has improved in England, the resection rate remains lower than it was in the early 2000s in some other countries. For example, we estimated that $32 \%$ of rectal cancer patients diagnosed in England in 2012-2013 (Scott et al, 2014) had an anterior resection compared with 45\% in Sweden in 1995-2004 (Jung et al 2009) (details of calculation available on request). Similarly, for stomach cancer, while in 2000-2005 in Ontario 45\% of patients were treated with curative intent, in 2011-2012 in England 38\% received surgery (Coburn et al, 2010; Taylor et al, 2014: p. 5).

In relation to lung cancer, although there has been a significant increase in resection rate and resection numbers in England, and an increase in the proportion of patients seen by specialists, there remains scope for improvement. The number of thoracic surgeons almost doubled to 84 WTE during 2006-2014 (personal communication: Sridhar Rathinam, Workforce Lead for the Society of Cardiothoracic Surgeons, 28 April 2015), but with over 30000 lung cancer patients diagnosed each year, the number remains relatively small. There is evidence that diagnostic procedures may be less aggressive in England than elsewhere. The National Lung Cancer Audit in England set a target (which has been met since 2009) of $75 \%$ for pathological confirmation of lung cancer (Health and Social Care Information Centre, 2012). In contrast in Sweden, 95\% of lung cancer patients diagnosed during 2002-2010 had their tumour verified by cytology or histology (Regionalt Cancercentrum Uppsala Örebro, 2012: p. 10, Table 3). There remains wide variation in the proportion of pathological confirmation by age group and region in England: for patients aged over 75, this is just $50 \%$ (Khakwani et al, 2013b). In a pan-European study on the quality of lung cancer care, only $4 \%$ of participating hospitals in England reported a histological confirmation rate higher 
than $90 \%$, compared with $87 \%$ of Danish participating hospitals (Blum et al, 2014).

These contrasts may reflect differences in clinical guidelines or access to diagnostic investigations. PET scan, usually in combination with $\mathrm{CT}$, is important in the assessment of the likelihood of mediastinal and/or extra-thoracic metastasis that would contraindicate treatment with curative intent. A PET-CT positive result may represent malignant infiltration but may also be a false positive for benign inflammation, therefore, histological investigation (biopsy by ultrasound-guided needle aspiration or mediastinoscopy) may be needed to confirm malignant disease (SchmidtHansen et al, 2014). In England, PET-CT is currently only recommended for patients potentially suitable for treatment with curative intent, while in Ontario PET-CT is recommended, if available, for all patients after a pathological diagnosis of NSCLC (Cancer Care Ontario, 2012). According to English guidelines, histological investigation of mediastinal lymph nodes is only indicated as an alternative to PET-CT (National Institute for Health and Clinical Excellence (NICE), 2011), whereas in Ontario and Denmark histological confirmation is recommended together with PET-CT, for all patients with centrally located tumours or with suspected mediastinal node involvement (Dansk Lunge Cancer Gruppe, 2014; Darling et al, 2010).

The international trend in breast cancer survival is unusual, in that the largest improvement in survival in all countries was experienced in the 1990s, and the 2000s have been characterised by a closing survival gap between England and Denmark and the four leading countries. This is probably because although there have been continued improvements in breast cancer diagnosis and treatment (including the introduction of targeted therapies, and improved usage of antihormonal treatments and chemotherapy), major innovations for breast cancer, such as adjuvant chemotherapy and tamoxifen, were introduced in the 1970s-1980s, and population screening had also been introduced in England before our study period. Furthermore, improvements in service organisation (e.g., use of MDTs and issuance of clinical guidelines) occurred earlier than for the other five cancers in England. By 1995, 1-year survival from breast cancer was already $95 \%$ or above in the four leading countries, and it is likely that the closing international survival gap arises mainly because of a 'ceiling effect' elsewhere.

Recent trends and future prospects. There was an acceleration in survival improvement in England in more recent years. The average annual improvement in survival was higher in 2005-2009 than in 2000-2004 for the gastrointestinal, lung and ovarian cancers, and higher in 2010-2012 than in 2005-2009 for rectal and ovarian cancers at 1 year, and lung cancer at 1 and 5 years. The recent acceleration in lung cancer survival improvement has been especially large, and the improvement in 5-year survival since 2006 has particular significance given the relatively static trend until then. This improvement coincides with the doubling of the resection rate for lung cancer in recent years (Page et al, 2011).

It is unclear whether these trends represent further closing of the international survival gap because data are not yet available for the comparator countries. However, there are indications that some novel therapies and approaches, which could have affected recent survival trends in the six countries, have been implemented later in England than elsewhere. For example, the introduction of stereotactic body radiotherapy (SBRT) as an alternative to surgery for early-stage lung cancer patients could have improved lung cancer survival at the population level, given that it widens access to treatment with curative intent to patients with contraindications for surgery (Haasbeek et al, 2012). Data are not yet available on the relative availability of SBRT in the six countries, but it was pioneered in Sweden (Lax et al, 1994), it was indicated in clinical guidelines in Denmark, Ontario and Sweden earlier than in England, and it has been available in some Danish and Swedish cancer centres from the early-mid-2000s (Jeppesen et al, 2013; Louie et al, 2014). Similarly, it is unclear how far there is variation between these countries in the implementation of ultra-radical surgery for ovarian cancer, and in the introduction of perioperative chemotherapy (Cunningham et al, 2006) and improvements in palliative oncology for stomach cancer (Bang et al, 2010). The international survival gap may narrow as England introduces innovations that are already implemented in other countries, or widen as such innovations become widespread in other countries first.

Equally, there is potential for a widening survival gap if reforms implemented earlier in England are now replicated elsewhere. For example, a national bowel cancer screening programme was introduced in England earlier than elsewhere (2006-2009), possibly contributing to some of the recent improvement in bowel cancer survival. However, all five other countries have now also implemented either national or regional bowel screening programmes, which often cover a wider age range than in England. Therefore, it is likely that if improvements in stage distribution or survival were effected by screening in England, they will also soon be effected elsewhere (Flitcroft et al, 2010; Zavoral et al, 2009).

Likewise, health system factors and national cancer policy were instrumental in driving improvements in cancer outcomes in England in the 2000s, but concerns have arisen about continuity of those system-level effects following reforms implemented since through the Health and Social Care Act 2012 (Cancer Research UK, 2012; National Audit Office, 2015). Since April 2013, commissioning services for cancer have been restructured, changing from 152 Primary Care Trusts to 211 Clinical Commissioning Groups; the 28 Cancer Networks, which worked to ensure consistency and quality in cancer services for more than a decade, have been disbanded, and key strategic policy posts within the Department of Health have been changed to advisory roles within NHS England, or dissolved. These reforms came at a time of financial austerity: the health service is under pressure to make unprecedented efficiency savings of $£ 20$ billion by 20142015 , and the average annual spend on cancer services per head of the population fell by $3.4 \%$ in 2010-2011 (Cancer Research UK, 2012). Such financial restrictions compound existing lower levels of cancer spending compared with other northwest European countries (Luengo-Fernandez et al, 2013).

There is already evidence that cancer services have been affected, with some performance targets having been missed for the first time (e.g., the target of a maximum 62-day wait between urgent GP referral and treatment for $85 \%$ of patients was not met during 2014-2015) (NHS England, 2015). Furthermore, although there is continued emphasis on outcomes monitoring in the reformed NHS, and cancer intelligence continues to improve, systems of formal accountability have been reshaped, implying risks to the continued dissemination and use of this intelligence to improve standards. This is compounded by increased restrictions on data access for research due to rising sensitivity around patient confidentiality (National Audit Office, 2015).

England's future trajectory towards closing the international gap in cancer survival is therefore uncertain, and continued international cancer survival surveillance is needed to monitor on-going progress. It will be important that such surveillance is age-specific, given evidence of the particularly wide gap in survival for older patients (Maringe et al, 2013; Walters et al, 2013)

\section{CONCLUSION}

One- and five-year survival from six common cancers in England was lower than in Australia, Canada, Norway and Sweden in 2005-2009. By 2010-2012 1-year survival in England remained 
lower than in 2005-2009 in the four leading countries for three of these cancers, and 5-year survival remained lower for five of these cancers. During 1995-1999 to 2005-2009, improvement in 1-year survival was generally higher in England than in Australia, Canada or Sweden. For breast cancer, survival at both 1 and 5 years in England improved more than in these countries or Norway. There has been notable acceleration in improvement in survival from lung cancer during 2010-2012, as well some acceleration for rectal and ovarian cancers.

The improvement in survival in England was partly due to innovations in diagnostics and treatment, although there is evidence that novel therapies were often implemented more quickly elsewhere. Other key drivers were strong strategic leadership, increased investment, and the creation of more stable and centralised commissioning structures to enhance observance of national guidelines, as well as increased availability of data for outcomes monitoring and local benchmarking. Survival in Denmark was similarly lower than in the other four countries in 1995-1999, but it generally improved faster than in England over the next decade, especially for rectal and lung cancers. This may be ascribed to particularly effective centralisation, specialisation and performance monitoring in Denmark in the 2000s.

In some instances, survival in England improved more than in Australia, Canada, Norway or Sweden during the 2000s, but future trends are uncertain in the context of health service reform and efficiency savings. Committed investment in centralised, specialised and accountable services for cancer patients will be essential for continued progress against the international survival gap.

\section{ACKNOWLEDGEMENTS}

This study was funded by an Early Diagnosis Policy Research Grant from Cancer Research UK to the Cancer Policy Programme at the London School of Hygiene and Tropical Medicine (award number C7923/A18348). SW, SBM and PM are supported by that award. We thank Helena Carreira, Rhea Harewood and Devon Spika (CONCORD Programme, Cancer Survival Group, London School of Hygiene and Tropical Medicine, UK) for their work on the international survival estimates and life tables and for the information on data quality control in the CONCORD-2 study. We thank Paul Dickman (Department of Medical Epidemiology and Biostatistics, Karolinska Institutet, Sweden), Tom Johannesen (Department of Registration, Norwegian Cancer Registry, Norway), Lorraine Shack (Department of Oncology, University of Calgary, Canada) and Sara Hiom (Cancer Research UK) for putting us in contact with clinical colleagues in their countries. We thank the following clinicians and oncologists for participating in this study and for providing information about the development of cancer control in their country: William Allum (Gastrointestinal Unit, Royal Marsden Hospital, UK), David Baldwin (Department of Respiratory Medicine, Nottingham City Hospital, UK), Peter Barrett-Lee (Academic Breast Unit, Velindre NHS Trust, UK), Jean-Marc Bourque (Institute of Cancer Policy, King's College London, UK), John Boyages (Macquarie University Cancer Institute, Macquarie University, Australia), William Evans (Department of Oncology, McMaster University, Canada), Tony Fields (Department of Oncology, University of Alberta, Canada), Paul Finan (John Goligher Colorectal Unit, St James's University Hospital, UK), Neville Hacker (Gynaecological Cancer Centre, Royal Hospital for Women, Australia), Lars Holmberg (Department of Surgical Sciences, Uppsala University, Sweden), Erik Jakobsen (Department of Thoracic Surgery, University of Southern Denmark, Denmark), Svetlana Lagercrantz (Department of Oncology-Pathology, Karolinska Institutet, Sweden), Marc Kerba (Tom Baker Cancer Centre, University of Calgary, Canada),
Mats Lindblad (Department of Surgical Gastroenterology, Karolinska University Hospital, Sweden), Michael Machesney (Colorectal Cancer Services, Barts Health NHS Trust, UK), Berit J. Mosgaard (Department of Gynecology, Juliane Marie Centre, University Hospital Rigshopitalet, Copenhagen, Denmark), Magnus Nilsson (Karolinska Institutet and Centre for Digestive Diseases, Karolinska University Hospital, Sweden), Andy Nordin (East Kent Gynaecological Oncology Centre, Queen Elizabeth the Queen Mother Hospital, UK), John Zalcberg (Cancer Research Program, School of Public Health and Preventive Medicine, Monash University, Australia).

\section{CONFLICT OF INTEREST}

The authors declare no conflict of interest.

\section{REFERENCES}

Allemani C, Weir HK, Carreira H, Harewood R, Spika D, Wang XS, Bannon F, Ahn JV, Johnson CJ, Bonaventure A, Marcos-Gragera R, Stiller C, Azevedo ESG, Chen WQ, Ogunbiyi OJ, Rachet B, Soeberg MJ, You H, Matsuda T, Bielska-Lasota M, Storm H, Tucker TC, Coleman MP. The CONCORD Working Group (2015) Global surveillance of cancer survival 1995-2009: analysis of individual data for 25,676,887 patients from 279 population-based registries in 67 countries (CONCORD-2). Lancet 385(9972): 977-1010.

Bang YJ, Van Cutsem E, Feyereislova A, Chung HC, Shen L, Sawaki A, Lordick F, Ohtsu A, Omuro Y, Satoh T, Aprile G, Kulikov E, Hill J, Lehle M, Ruschoff J, Kang YK, ToGA Trial Investigators (2010) Trastuzumab in combination with chemotherapy versus chemotherapy alone for treatment of HER2-positive advanced gastric or gastrooesophageal junction cancer (ToGA): a phase 3, open-label, randomised controlled trial. Lancet 376(9742): 687-697.

Beckett P, Woolhouse I, Stanley R, Peake MD (2012) Exploring variations in lung cancer care across the UK-the 'story so far' for the National Lung Cancer Audit. Clin Med 12(1): 14-18.

Berrino F, Sant M, Verdecchia A, Capocaccia R, Hakulinen T, Estève J (eds) (1995) Survival of Cancer Patients in Europe: The EUROCARE Study (IARC Scientific Publications No. 132). International Agency for Research on Cancer: Lyon, France.

Birkmeyer JD, Stukel TA, Siewers AE, Goodney PP, Wennberg DE, Lucas FL (2003) Surgeon volume and operative mortality in the United States. $N$ Engl J Med 349(22): 2117-2127.

Blum TG, Rich A, Baldwin D, Beckett P, De Ruysscher D, Faivre-Finn C, Gaga M, Gamarra F, Grigoriu B, Hansen NC, Hubbard R, Huber RM, Jakobsen E, Jovanovic D, Konsoulova A, Kollmeier J, Massard G, McPhelim J, Meert AP, Milroy R, Paesmans M, Peake M, Putora PM, Scherpereel A, Schonfeld N, Sitter H, Skaug K, Spiro S, Strand TE, Taright S, Thomas M, van Schil PE, Vansteenkiste JF, Wiewrodt R, Sculier JP (2014) The European initiative for quality management in lung cancer care. Eur Respir J 43(5): 1254-1277.

Brenner H, Gefeller O (1996) An alternative approach to monitoring cancer patient survival. Cancer 78(9): 2004-2010.

Brenner H, Rachet B (2004) Hybrid analysis for up-to-date long-term survival rates in cancer registries with delayed recording of incident cases. Eur J Cancer 40(16): 2494-2501.

Butler J, Gildea C, Poole J, Meechan D, Nordin A (2015) Specialist surgery for ovarian cancer in England. Gynecol Oncol; e-pub ahead of print 31 March 2015; doi:10.1016/j.ygyno.2015.03.003.

Canadian Strategy for Cancer Control Governing Council (2006) The Canadian Strategy for Cancer Control: A Cancer Plan for Canada. CSCC Governing Council: Toronto, ON, Canada.

Cancer Care Ontario (2004) Ontario Cancer Plan 2005-2008. Cancer Care Ontario: Toronto, ON, Canada.

Cancer Care Ontario (2012) Lung Cancer Diagnosis Pathway. Cancer Care Ontario: Toronto, ON, Canada.

Cancer Institute New South Wales (2004) New South Wales Cancer Plan 2004-2006. Cancer Institute NSW: Sydney, NSW, Australia. 
Cancer Research UK (2012) Cancer Services: Reverse, Pause or Progress? Cancer Research UK: London, UK.

Clerc-Urmès I, Grzebyk M, Hédelin G (2014) Net survival estimation with stns. Stata J 14: 87-102.

Coburn NG, Lourenco LG, Rossi SE, Gunraj N, Mahar AL, Helyer LK, Law C, Rabeneck L, Paszat L (2010) Management of gastric cancer in Ontario. J Surg Oncol 102(1): 54-63.

Coleman MP, Forman D, Bryant H, Butler J, Rachet B, Maringe C, Nur U, Tracey E, Coory M, Hatcher J, McGahan CE, Turner D, Marrett L, Gjerstorff ML, Johannesen TB, Adolfsson J, Lambe M, Lawrence G, Meechan D, Morris EJ, Middleton R, Steward J, Richards MA, The ICBP Module 1 Working Group (2011) Cancer survival in Australia, Canada, Denmark, Norway, Sweden, and the UK, 1995-2007 (the International Cancer Benchmarking Partnership): an analysis of population-based cancer registry data. Lancet 377(9760): 127-138.

Corazziari I, Quinn M, Capocaccia R (2004) Standard cancer patient population for age standardising survival ratios. Eur J Cancer 40(15): 2307-2316.

Cromwell D, Palser T, van der Meulen JH, Hardwick R, Riley S, Greenaway K, Dean S (2010) National Oesophago-Gastric Cancer Audit 2010. The Royal College of Surgeons of England: London, UK.

Cunningham D, Allum WH, Stenning SP, Thompson JN, Van de Velde CJ, Nicolson M, Scarffe JH, Lofts FJ, Falk SJ, Iveson TJ, Smith DB, Langley RE, Verma M, Weeden S, Chua YJ, Magic Trial Participants (2006) Perioperative chemotherapy versus surgery alone for resectable gastroesophageal cancer. N Engl J Med 355(1): 11-20.

Dahlberg M, Påhlman L, Bergström R, Glimelius B (1998) Improved survival in patients with rectal cancer: a population-based register study. Br J Surg 85(4): 515-520.

Dalkey NC, Helmer O (1963) An experimental application of the Delphi method to the use of experts. Manage Sci 9(3): 458-467.

Danish National Board of Health (2000) The National Cancer Plan Summary. National Board of Health: Copenhagen, Denmark.

Dansk Lunge Cancer Gruppe (2014) Lungecancer visitation, diagnose \& stadienddeling. Dansk Lunge Cancer Gruppe: Odense, Denmark.

Darling G, Dickie A, Malthaner R, Kennedy E, Tey R, Invasive Mediastinal Staging Expert Panel (2010) Invasive Mediastinal Staging of Non-small-cell Lung Cancer: A Clinical Practice Guideline. Cancer Care Ontario: Toronto, ON, Canada.

Department of Health (2000) The NHS Cancer Plan. Department of Health: London, UK.

Department of Health (2007) Cancer Reform Strategy. Department of Health: London, UK.

Department of Health (2011) Improving Outcomes: A Strategy for Cancer. Department of Health: London, UK.

Expert Advisory Group on Cancer (1995) A Policy Framework for Commissioning Cancer Services. Department of Health: London, UK.

Flitcroft KL, Salkeld GP, Gillespie JA, Trevena LJ, Irwig LM (2010) Fifteen years of bowel cancer screening policy in Australia: putting evidence into practice? Med J Aust 193(1): 37-42.

Groene O, Chadwick G, Riley S, Hardwick RH, Crosby T, Greenaway K, Allum W, Cromwell DA (2014) Re-organisation of oesophago-gastric cancer services in England and Wales: a follow-up assessment of progress and remaining challenges. BMC Res Notes 7: 24.

Guren MG, Kørner H, Pfeffer F, Myklebust TÅ, Eriksen MT, Edna TH, Larsen SG, Knudsen KO, Nesbakken A, Wasmuth HH, Vonen B, Hofsli E, Færden AE, Brændengen M, Dahl O, Steigen SE, Johansen MJ, Lindsetmo RO, Drolsum A, Tollåli G, Dørum LM, Møller B, Wibe A (2015) Nationwide improvement of rectal cancer treatment outcomes in Norway, 1993-2010. Acta Oncol; e-pub ahead of print 30 April 2015; doi:10.3109/0284186X.2015.1034876.

Haasbeek CJ, Palma D, Visser O, Lagerwaard FJ, Slotman B, Senan S (2012) Early-stage lung cancer in elderly patients: a population-based study of changes in treatment patterns and survival in the Netherlands. Ann Oncol 23(10): 2743-2747.

Hannan EL, Radzyner M, Rubin D, Dougherty J, Brennan MF (2002) The influence of hospital and surgeon volume on in-hospital mortality for colectomy, gastrectomy, and lung lobectomy in patients with cancer. Surgery 131(1): 6-15.

Hansen MH, Kjaeve J, Revhaug A, Eriksen MT, Wibe A, Vonen B, Norwegian Rectal Cancer Group (2007) Impact of radiotherapy on local recurrence of rectal cancer in Norway. Br J Surg 94(1): 113-118.
Health and Social Care Information Centre (2012) National Lung Cancer Audit Annual Report 2012: Report for the Audit Period 2011. Health and Social Care Information Centre: Leeds, UK.

Health and Social Care Information Centre (2014) National Lung Cancer Audit Annual Report 2014: Report for the Audit Period 2013. Health and Social Care Information Centre: Leeds, UK.

Hegney D, Pearce S, Rogers-Clark C, Martin-McDonald K, Buikstra E (2005) Close, but still too far. The experience of Australian people with cancer commuting from a regional to a capital city for radiotherapy treatment. Eur J Cancer Care (Engl) 14(1): 75-82.

House of Commons Committee of Public Accounts (2006) The NHS Cancer Plan: A Progress Report. House of Commons Stationery Office: London, $\mathrm{UK}$.

House of Commons Committee of Public Accounts (2011) Delivering the Cancer Reform Strategy. HC667, Session 2010. The Stationery Office: London, UK.

Hsu C-C, Sandford BA (2007) The Delphi technique: making sense of consensus. Prac Assess Res Eval 12(10). Available at http://pareonline.net/ $\mathrm{pdf} / \mathrm{v} 12 \mathrm{n} 10 . \mathrm{pdf}$.

Jensen LS, Bendixen A, Kehlet H (2007) Organisation and early outcomes of major upper gastrointestinal cancer surgery in Denmark 1996-2004. Scand J Surg 96(1): 41-45.

Jensen LS, Nielsen H, Mortensen PB, Pilegaard HK, Johnsen SP (2010) Enforcing centralization for gastric cancer in Denmark. Eur J Surg Oncol 36(Suppl 1): S50-S54.

Jeppesen SS, Schytte T, Jensen HR, Brink C, Hansen O (2013) Stereotactic body radiation therapy versus conventional radiation therapy in patients with early stage non-small cell lung cancer: an updated retrospective study on local failure and survival rates. Acta Oncol 52(7): 1552-1558.

Jung B, Påhlman L, Johansson R, Nilsson E (2009) Rectal cancer treatment and outcome in the elderly: an audit based on the Swedish Rectal Cancer Registry 1995-2004. BMC Cancer 9: 68.

Khakwani A, Rich AL, Powell HA, Tata LJ, Stanley RA, Baldwin DR, Duffy JP, Hubbard RB (2013a) Lung cancer survival in England: trends in non-small-cell lung cancer survival over the duration of the National Lung Cancer Audit. Br J Cancer 109(8): 2058-2065.

Khakwani A, Rich AL, Tata LJ, Powell HA, Stanley RA, Baldwin DR, Hubbard RB (2013b) The pathological confirmation rate of lung cancer in England using the NLCA database. Lung Cancer 79(2): 125-131.

Kodeda K, Nathanaelsson L, Jung B, Olsson H, Jestin P, Sjövall A, Glimelius B, Påhlman L, Syk I (2013) Population-based data from the Swedish Colon Cancer Registry. Br J Surg 100(8): 1100-1107.

Lax I, Blomgren H, Naslund I, Svanstrom R (1994) Stereotactic radiotherapy of malignancies in the abdomen. Methodological aspects. Acta Oncol 33(6): 677-683.

Louie AV, Rodrigues GB, Palma DA, Senan S (2014) Measuring the population impact of introducing stereotactic ablative radiotherapy for stage I non-small cell lung cancer in Canada. Oncologist 19(8): $880-885$.

Luengo-Fernandez R, Leal J, Gray A, Sullivan R (2013) Economic burden of cancer across the European Union: a population-based cost analysis. Lancet Oncol 14(12): 1165-1174.

Lykke J, Roikjær O, Jess P (2013) The majority of surgical departments adhere to national Danish guidelines for surveillance after colorectal cancer surgery. Dan Med J 60(7): A4664.

Maringe C, Walters S, Butler J, Coleman MP, Hacker N, Hanna L, Mosgaard BJ, Nordin A, Rosen B, Engholm G, Gjerstorff ML, Hatcher J, Borge Johannesen T, McGahan CE, Meechan D, Middleton R, Tracey E, Turner D, Richards MA, Rachet B, ICBP Module 1 Working Group (2012) Stage at diagnosis and ovarian cancer survival: evidence from the International Cancer Benchmarking Partnership. Gynecol Oncol 127: 75-82.

Maringe C, Walters S, Rachet B, Butler J, Fields T, Finan PJ, Maxwell R, Nedrebø B, Påhlman L, Sjövall A, Spigelman A, Engholm G, Gavin A, Gjerstorff ML, Hatcher J, Borge Johannesen T, Morris EJ, McGahan CE, Tracey E, Turner D, Richards MA, Coleman MP, ICBP Module 1 Working Group (2013) Stage at diagnosis and colorectal cancer survival in six highincome countries: a population-based study of patients diagnosed during 2000-7. Acta Oncol 52: 919-932.

Martling A, Holm T, Rutqvist LE, Johansson H, Moran BJ, Heald RJ, Cedermark B (2005) Impact of a surgical training programme on rectal cancer outcomes in Stockholm. Br J Surg 92(2): 225-229. 
McCulloch P, Ward J, Tekkis PP, Ascot Group of Surgeons, British Oesophago-Gastric Cancer Group (2003) Mortality and morbidity in gastro-oesophageal cancer surgery: initial results of ASCOT multicentre prospective cohort study. BMJ 327(7425): 1192-1197.

Meyer HJ (2005) The influence of case load and the extent of resection on the quality of treatment outcome in gastric cancer. Eur J Surg Oncol 31(6): 595-604.

Morris EJ, Taylor EF, Thomas JD, Quirke P, Finan PJ, Coleman MP, Rachet B, Forman D (2011) Thirty-day postoperative mortality after colorectal cancer surgery in England. Gut 60(6): 806-813.

National Audit Office (2015) Progress in Improving Cancer Services and Outcomes in England. National Audit Office: London, UK.

National Institute for Health and Clinical Excellence (NICE) (2011) Lung cancer: The Diagnosis and Treatment of Lung Cancer. NICE clinical guideline 121. NICE: London, UK.

NHS England (2015) Waiting Times for Suspected and Diagnosed Cancer Patients: 2014-15 Annual Report. Available at http://www.england.nhs.uk/ statistics/wp-content/uploads/sites/2/2015/05/CancerWaitingTimes AnnualReport_201415_Final.pdf (accessed 18 June 2015).

Norwegian Official Reports No. 20: 1997 (1997) Care and Knowledge! The Norwegian Cancer Plan-English Summary. Ministry of Health and Care Services: Oslo, Norway.

Olesen F, Hansen RP, Vedsted P (2009) Delay in diagnosis: the experience in Denmark. Br J Cancer 101(S2): S5-S8.

Ottesen B, Iversen MG, Kehlet H (2009) Surgical treatment for ovarian cancer in Denmark 2004-2007. Ugeskr Laeger 171(4): 217-220.

Page RD, McShane J, Kinsman R on behalf of the Society for Cardiothoracic Surgery in Great Britain \& Ireland (2011) Second National Thoracic Surgery Activity and Outcomes Report 2011. Dendrite Clinical Systems Ltd: Henley-on-Thames, Report no. 978-0-9568154-1-5.

Påhlman L, Bohe M, Cedermark B, Dahlberg M, Lindmark G, Sjodahl R, Ojerskog B, Damber L, Johansson R (2007) The Swedish rectal cancer registry. Br J Surg 94(10): 1285-1292.

Pohar Perme M, Stare J, Estève J (2012) On Estimation in Relative Survival. Biometrics 68(1): 113-120.

Probst HB, Hussain ZB, Andersen O (2012) Cancer patient pathways in Denmark as a joint effort between bureaucrats, health professionals and politicians-A national Danish project. Health Policy 105(1): 65-70.

Rachet B, Maringe C, Nur U, Quaresma M, Shah A, Woods LM, Ellis L, Walters S, Forman D, Steward J, Coleman MP (2009) Population-based cancer survival trends in England and Wales up to 2007: an assessment of the NHS cancer plan for England. Lancet Oncol 10(4): 351-369.

Regionalt Cancercentrum Norr (2014) Rektalcancer Nationell kvalitetsrapport för diagnosår 2013 från Svenska Kolorektalcancerregistret. Regionalt cancercentrum, Norr: Umeå, Sweden.

Regionalt Cancercentrum Uppsala Örebro (2012) Lungcancer i Sverige Nationellt register för lungcancer Regionala jämförelser 2002-2010. Regionalt Cancer Centrum, Uppsala Örebror: Uppsala, Sweden.

Riaz SP, Linklater KM, Page R, Peake MD, Møller H, Lüchtenborg M (2012) Recent trends in resection rates among non-small cell lung cancer patients in England. Thorax 67(9): 811-814.

Rich AL, Tata LJ, Free CM, Stanley RA, Peake MD, Baldwin DR, Hubbard RB (2011a) How do patient and hospital features influence outcomes in small-cell lung cancer in England? Br J Cancer 105(6): 746-752.

Rich AL, Tata LJ, Free CM, Stanley RA, Peake MD, Baldwin DR, Hubbard RB (2011b) Inequalities in outcomes for non-small cell lung cancer: the influence of clinical characteristics and features of the local lung cancer service. Thorax 66(12): 1078-1084.

Rich AL, Tata LJ, Stanley RA, Free CM, Peake MD, Baldwin DR, Hubbard RB (2011c) Lung cancer in England: information from the National Lung Cancer Audit (LUCADA). Lung Cancer 72(1): 16-22.

Richards MA (2009) The size of the prize for earlier diagnosis of cancer in England. Br J Cancer 101(Suppl 2): S125-S129.

Schmidt-Hansen M, Baldwin DR, Hasler E, Zamora J, Abraira V, Roque IFM (2014) PET-CT for assessing mediastinal lymph node involvement in patients with suspected resectable non-small cell lung cancer. Cochrane Database Syst Rev 11: Cd009519.

Scott N, Hill J, Kelly S, Fearnhead N, Kuryba A, Walker K, van der Meulen J, Greenaway G, Meace C, Bunn E (2014) National Bowel Cancer Audit Report 2014. Health and Social Care Information Centre: Leeds, UK.

Scott N, Hill J, Smith J, Walker K, Kuryba A, van der Meulen J, Greenaway G, Yelland A, Meace C (2013) National Bowel Cancer Audit Annual Report 2013. Health and Social Care Information Centre: Leeds, UK.

Society for Cardiothoracic Surgery in Great Britain and Ireland (undated) Provisional 2013-14 Thoracic Returns Data Released. Available at http://www.scts.org/professionals/audit_outcomes/thoracic.aspx (accessed 17 May 2015).

Starr LK, Osler M, Steding-Jessen M, Frederiksen BL, Jakobsen E, Østerlind K, Schüz J, Johansen C, Dalton SO (2013) Socioeconomic position and surgery for early-stage non-small-cell lung cancer: a population-based study in Denmark. Lung Cancer 79(3): 262-269.

Taylor A, Chadwick G, Groene O, Cromwell D, Hardwick R, Riley S, Crosby T, Greenaway K (2014) National Oesophago-Gastric Cancer Audit Progress Report 2014. The Royal College of Surgeons of England: London, UK.

The NHS Information Centre (2006) National Lung Cancer Audit: Report for the Audit Period 2005. NHS IC: Leeds, UK.

Tracey E, Hacker NF, Young J, Armstrong BK (2014) Effects of access to and treatment in specialist facilities on survival from epithelial ovarian cancer in Australian women: a data linkage study. Int J Gynecol Cancer 24(7): $1232-1240$.

Walters S, Maringe C, Coleman MP, Peake MD, Butler J, Young N, Bergström S, Hanna L, Jakobsen E, Kölbeck K, Sundstrøm S, Engholm G, Gavin A, Gjerstorff ML, Hatcher J, Børge Johannesen T, Linklater KM, McGahan CE, Steward J, Tracey E, Turner D, Richards MA, Rachet B, ICBP Module 1 Working Group (2013) Lung cancer survival and stage at diagnosis in Australia, Canada, Denmark, Norway, Sweden and the United Kingdom: a population-based study, 2004-2007. Thorax 68: 551-564.

Wibe A, Møller B, Norstein J, Carlsen E, Wiig JN, Heald RJ, Langmark F, Myrvold HE, Søreide O, Norwegian Rectal Cancer Group (2002) A national strategic change in treatment policy for rectal cancer implementation of total mesorectal excision as routine treatment in Norway. A national audit. Dis Colon Rectum 45(7): 857-866.

Zavoral M, Suchanek S, Zavada F, Dusek L, Muzik J, Seifert B, Fric P (2009) Colorectal cancer screening in Europe. World J Gastroenterol 15(47): 5907-5915.

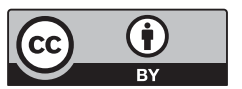

This work is licensed under the Creative Commons Attribution 4.0 International License. To view a copy of this license, visit http://creativecommons.org/licenses/by/4.0/

Supplementary Information accompanies this paper on British Journal of Cancer website (http://www.nature.com/bjc) 